\title{
Tanaman Apu-Apu (Pistia stratiotes L) dengan Penambahan Zeolit sebagai Agen Fitoremediasi Air Terkontaminasi Logam Kadmium (Cd), Tembaga (Cu) Dan Timbal (Pb)
}

\author{
Hasmalina Nasution, Siti Fatimah, Fitra Perdana, Sri Hilma Siregar \\ Prodi. Kimia, Fakultas MIPA dan Kesehatan, Universitas Muhammadiyah Riau \\ JL. Tuanku Tambusai, Kota Pekanbaru, Provinsi Riau- Indonesia \\ Correspondence e-mail: hasmalinanst@umri.ac.id
}

\begin{abstract}
ABSTRAK
Penelitian ini bertujuan untuk mengetahui penurunan kadar logam berat $(\mathrm{Cd}, \mathrm{Cu}$ dan $\mathrm{Pb})$ dalam air yang terkontaminasi logam berat dan mengetahui pengaruh perlakuan terhadap penurunan konsentrasi logam berat dalam air. Penelitian ini menggunakan rancangan acak lengkap (RAL) dengan 4 Perlakuan yaitu P1 (0 gr apu-apu + 150 gr zeolit), P2 (50 gr apu-apu + 100 gr zeolit), P3 (100 gr apu-apu + 50 gr zeolit) dan P4 (150 gr apu-apu +0 gr zeolit). Parameter utama dalam penelitian ini yaitu penurunan konsentrasi dalam air. Analisa data yang digunakan adalah analisa ANOVA untuk melihat pengaruh perlakuan terhadap penurunan logam. Analisa kadar logam $(\mathrm{Cd}, \mathrm{Cu}$ dan $\mathrm{Pb})$ dengan menggunakan spektrofotometer serapan atom (SSA). Persentase Penurunan kadar Cd tertinggi yaitu $73.80 \%$ sedangkan yang terendah $69.90 \%$, Persentase Penurunan kadar Cu tertinggi yaitu $89.46 \%$ sedangkan yang terendah $42.81 \%$, dan Persentase Penurunan kadar $\mathrm{Pb}$ tertinggi yaitu $99.07 \%$ sedangkan yang terendah $81.24 \%$, Nilai Penurunan kadar (Cd, Cu dan Pb) tertinggi diperoleh oleh P3. Hasil uji ANOVA menunjukkan bahwa terdapat pengaruh yang nyata perlakuan terhadap penurunan konsentrasi dalam air pada taraf nyata $(\mathrm{p}<0,05)$. Hasil penentuan uji presisi dan linearitas menunjukkan bahwa metode yang digunakan memiliki linearitas serta presisi yang baik.
\end{abstract}

Kata Kunci : Analisis Varians (ANOVA), Apu-Apu, Fitoremediasi, Kadmium, Spektrofotometer Serapan Atom (SSA), Tembaga, Timbal, Zeolit

Received: April 2021, Accepted : Mai 2021 - Jurnal Photon Vol.11 No.2

DOI : https://doi.org/10.37859/jp.v17i2.2770

PHOTON is licensed under a Creative Commons Attribution-ShareAlike 4.0 International License 


\section{Introduction}

Air merupakan kebutuhan pokok yang sangat penting untuk berbagai keperluan dalam setiap kehidupan mahluk hidup (Razia et al., 2017). Penurunan kualitas perairan terjadi karena eksploitasi lingkungan secara berlebihan dan aktivitas manusia (Bahri et al., 2015). Perkembangan teknologi tersebut memberikan dampak lain yaitu dengan adanya hasil samping sehingga muncul masalah pencemaran (Rahayu et al., 2014).

Pencemaran air adalah ancaman yang banyak dikhawatirkan oleh manusia karena air merupakan sumber kehidupan (Naslilmuna et al., 2018). Salah satu polutan tersebut adalah adanya logam berat yang terdapat pada air seperti kadmium $(\mathrm{Cd})$, tembaga $(\mathrm{Cu})$ dan timbal $(\mathrm{Pb})$. Keberadaan logam menjadi perhatian penting karena senyawa ini bersifat toksis, non biodegradable dan mempunyai tendensi yang terakumulasi dalam organisme hidup (Raziah et al., 2017). Menurut Peraturan Pemerintah RI No 82 Tahun 2001, batas maksimum kandungan logam kadmium dalam air yaitu 0,01 mg/L, untuk tembaga $0,02 \mathrm{mg} / \mathrm{L}$ dan untuk timbal $0,03 \mathrm{mg} / \mathrm{L}$. Untuk mengatasi permasalahan pencemaran air limbah yang mengandung logam berat, telah dikembangkan teknologi alternatif yang dapat membantu proses pengolahannya yaitu dengan teknologi fitoremediasi (Caroline et al., 2015). Fitoremediasi adalah penggunaan tumbuhan untuk menghilangkan polutan dari tanah atau perairan yang terkontaminasi (Rondonuwu, 2014). Teknik fitoremediasi dipilih sebagai upaya untuk merehabilitasi lingkungan yang tercemar karena dianggap teknologi yang inovatif, ekonomis, dan relatif aman terhadap lingkungan (Sidauruk dan Patricius, 2015; Astuti et al., 2018; Novita et al., 2019). Fitoremediasi umumnya mengunakan tumbuhan akuatik dalam lahan basah buatan sebagai pengolahan perairan dari pencemaran limbah cair. (Irawanto dan Baroroh, 2017). Namun kebanyakan orang masih belum menyadari manfaat keberadaan tumbuhan akuatik di alam. Berdasarkan Irawanto (2010) menyebutkan bahwa tumbuhan akuatik dapat berperan sebagai pengelola polutan/limbah cair. Salah satu contoh tanaman yang dapat digunakan sebagai fitoremediator adalah tanaman apu-apu (P.stratiotes L) (Irawanto et al., 2017). Tumbuhan akuatik apu-apu (P.stratiotes L) termasuk dalam famili Araceae yang tumbuh mengapung pada permukaan air dengan akar-akarnya yang menggantung terendam di bawah bagian daunnya yang mengambang. (Mardikaningtyas et al., 2016). Menurut Ugya (2015) tanaman apu-

Received: April 2021, Accepted : Mai 2021 - Jurnal Photon Vol.11 No.2

DOI : https://doi.org/10.37859/jp.v11i2.2770

PHOTON is licensed under a Creative Commons Attribution-ShareAlike 4.0 International License 
apu (P.stratiotes L) merupakan agen yang efektif untuk mengurangi dan menghilangkan berbagai logam berat seperti Hg, Cd, Mn, Ag, Pb, Zn di sungai Romi, Nigeria. Penelitian lain juga menghasilkan hal yang sama yakni apu-apu (P.stratiotes L) memiliki potensi dalam menyerap dan menurunkan kadar logam berat timbal pada perairan sehingga dapat digunakan sebagai agen fitoremediasi dalam memperbaiki kualitas suatu perairan yang tercemar (Oktaviani, 2014). Yasar et al (2013) dalam penelitiannya, juga menyimpulkan bahwa apu-apu (P.stratiotes L) merupakan tanaman akumulator terbaik untuk mengurangi logam berat di lingkungan. Penelitian oleh Abu bakar et al (2014) menyimpulkan bahwa P.stratiotes L merupakan fitoremediator yang sangat baik untuk rhizofiltrasi logam berat $(\mathrm{Pb}, \mathrm{Cr}, \mathrm{Ni})$ dari limbah cair. Dari hasil penelitian yang dilakukan Barorah et al (2018) diketahui bahwa Tumbuhan akuatik apu-apu (Pistia stratiotes L) efektif menurunkan logam berat Cu 2 ppm sebesar $94 \%$ dan 5 ppm sebesar 90\%. Penelitian oleh Rahayuningtyas et al (2018) menyimpulkan bahwa apu-apu efektif dalam menurunkan kadar timbal $(\mathrm{Pb})$ pada air irigasi pertanian dengan waktu kontak 12 hari yaitu 99,27\%. Paramitasari (2014) dalam penelitiannya menyimpulkan bahwa apu-apu menurunkan logam berat timbal $(\mathrm{Pb})$ dengan konsentrasi $1 \mathrm{ppm}$. Dari penelitian yang dilakukan Cahyanto et al (2018) diketahui bahwa menunjukkan apu-apu mempunyai kemampuan fitoremediasi Kromium (Cr) yang tinggi (efisiensi diatas 75\%) pada konsentrasi air limbah 25\%.

Upaya meningkatkan penyerap logam berat oleh apu-apu (Pistia stratiotes L) diperlukan penambahan batu zeolit sebagai adsorben. Metode adsorpsi dapat menyerap logam berat pada limbah cair ataupun perairan dan memiliki sifat selektivitas yang tinggi. Adsorben yang banyak digunakan adalah zeolit. (Renni et al., 2018). Menurut Suyanta et al (2016) dalam penelitiannya menyimpulkan bahwa zeolit efektif menurunkan logam Cu hingga 37,1698\% dan 35,9976\%. Penelitian oleh Nurafifah (2016) dapat diketahui bahwa kombinasi antara kiambang dan zeolit efektif dalam menurunkan logam berat kadmium (Cd) dengan rata-rata penurunan yaitu 98,7\%, 97,1\%, 97,2\% dan 95,8\%. Berdasarkan uraian penelitian yang telah dilakukan oleh beberapa peneliti diatas, maka peneliti tertarik melakukan penelitian mengenai fitoremediasi air tercemar logam berat $(\mathrm{Cd}, \mathrm{Cu}$ dan $\mathrm{Pb})$ mengunakan tanaman apuapu (Pistia stratiotes L) dengan penambahan zeolit. Tujuan dari penelitian ini untuk mengetahui

Received: April 2021, Accepted : Mai 2021 - Jurnal Photon Vol.11 No.2

DOI : https://doi.org/10.37859/jp.v11i2.2770

PHOTON is licensed under a Creative Commons Attribution-ShareAlike 4.0 International License 
kemampuan tumbuhan apu- apu (Pistia stratiotes L) dalam mengurangi konsentrasi logam berat kadmium $(\mathrm{Cd})$, tembaga $(\mathrm{Cu})$ dan timbal $(\mathrm{Pb})$ pada air dan pengaruh penambahan zeolit sebagai absorben terhadap penurunan logam berat kadmium $(\mathrm{Cd})$, tembaga $(\mathrm{Cu})$ dan timbal $(\mathrm{Pb})$ dalam air. Dimana hasilnya dapat digunakan sebagai upaya dalam mengurangi pencemaran pada air.

\section{The Methods}

Penelitian yang dilakukan adalah Fitoremediasi air simulasi yang tercemar logam berat $(\mathrm{Cd}, \mathrm{Cu}$ dan $\mathrm{Pb})$ dengan menggunakan tumbuhan akuatik P.stratiotes L dengan penambahan zeolit. Penelitian ini menggunakan Rancangan Acak Lengkap (RAL) dengan menggunakan 4 perlakuan. Tumbuhan P.stratiotes L yang berwarna hijau dan dalam keadaan segar dibersihkan terlebih dahulu akarnya dari kotoran. Kemudian diaklimatisasi selama 5 hari agar dapat beradaptasi dengan lingkungan baru. Tahap ini mengunakan wadah plastik $(27,5 \times 24 \mathrm{~cm})$ kapasitas 5 Liter air yang mengandung logam berat $(\mathrm{Cd}$, $\mathrm{Cu}$ dan $\mathrm{Pb}$ ) dengan konsentrasi 10 ppm dengan perlakuan sebagai berikut :

1. P1 : Menggunakan 0 gram apu-apu +150 gram zeolit

2. P2 : Menggunakan 50 gram apu-apu +100 gram zeolit

3. P3 : Menggunakan 100 gram apu-apu +50 gram zeolit

4. P4 : Menggunakan 150 gram apu-apu +0 gram zeolit

Perlakuan Fitoremediasi selama 14 hari dengan pengamatan selama 2 hari sekali (Irawanto et al., 2017). Pengamatan berupa perubahan morfologi tumbuhan seperti warna daun dan bentuk daun. Analisa kadar kadmium (Cd) menggunakan metode SNI 6989.16:2009, analisa kadar tembaga (Cu) pada air limbah menggunakan metode SNI 6989.6:2009 dan analisa kadar timbal $(\mathrm{Pb})$ pada air limbah menggunakan metode SNI 6989.8:2009 instrument SSA. Panjang gelombang analisa Cd yaitu 228,8 $\mathrm{nm}$, pada analisa $\mathrm{Cu}$ yaitu $324,8 \mathrm{~nm}$ dan pada analisa $\mathrm{Pb}$ yaitu $283,3 \mathrm{~nm}$. Data dari penelitian ini disajikan dalam bentuk grafik dan serta dianalisis secara statistik metode uji One Way Anova, H0 : Tidak ada pengaruh perlakuan terhadap penurunan konsentrasi logam dalam air, jika $\mathrm{F}$ hitung $<\mathrm{F}$ tabel,sedangkan H1 : Ada pengaruh perlakuan terhadap penurunan konsentrasi logam dalam air, jika

Received: April 2021, Accepted : Mai 2021 - Jurnal Photon Vol.11 No.2

DOI : https://doi.org/10.37859/jp.v11i2.2770

PHOTON is licensed under a Creative Commons Attribution-ShareAlike 4.0 International License 
F hitung $>$ F tabel

\section{Alat dan Bahan}

Alat yang digunakan:

Alat yang digunakan adalah Timbangan Analitik dengan ketelitian sampai dengan 0,0001 g,Peralatan gelas, Penangas listrik (Hot plate), pH meter, Spatula dan Spektrofotometer Serapan Atom (SSA).

\section{Bahan yang digunakan:}

Bahan yang digunakan apu-apu, wadah plastik $27,5 \times 24 \mathrm{~cm}$, zeolite, air akuades, asam nitrat $\left(\mathrm{HNO}_{3}\right)$ pekat p.a, $\mathrm{CdCl}_{2}, \mathrm{Cu}\left(\mathrm{NO}_{3}\right)_{2}$ dan $\mathrm{Pb}\left(\mathrm{NO}_{3}\right)_{2}$.

\section{Result And Discussion}

\section{Penurunan Konsentrasi Kadmium (Cd) Dalam Air}

Dari hasil penelitian menunjukkan bahwa rata-rata konsentrasi Kadmium (Cd) dalam air pada ke 4 perlakuan P1 hingga P4 secara berturut adalah $3.0101 \mathrm{mg} / \mathrm{L}, 2.7142 \mathrm{mg} / \mathrm{L}, 2.6196 \mathrm{mg} / \mathrm{L}$ dan 2.6916 mg/L. Dalam penelitian Nurfitriana (2019) bahwa yang terjadi menunjukkan adanya penyerapan logam kadmium pada air oleh tanaman apu- apu. Dapat dilihat bahwa penurunan konsentrasi yang terjadi menunjukkan bahwa tanaman apu-apu (Pistia Stratiotes) merupakan tanaman hiperakumulator yang mampu menyerap zat pencemar logam.

Berdasarkan data dapat dijelaskan bahwa terdapat perbedaan signifikan pada setiap perlakuan terhadap konsentrasi Cd logam berat kadmium seseudah Fitoremediasi. Konsentrasi logam kadmium setelah fitoremedisi terendah pada perlakuan P3 (100 gr apu-apu + $50 \mathrm{gr}$ zeolit) yaitu $2.6196 \mathrm{mg} / \mathrm{L}$ sedangkan yang terti pada perlakuan P1(0 gr apu-apu +150 gr zeolit). Hal ini terjadi karena apu-apu termasuk tanaman hiperakumulator yang dapat menyerap logam berat pada akarnya . Jadi semakin banyak tanaman apu- apu yang digunakan semakin besar penyerapan logam kadmium.

Received: April 2021, Accepted : Mai 2021 - Jurnal Photon Vol.11 No.2 DOI : https://doi.org/10.37859/jp.v17i2.2770 PHOTON is licensed under a Creative Commons Attribution-ShareAlike 4.0 $\underline{\text { International License }}$ 


\section{Jurnal Sains dan Kesehatan}

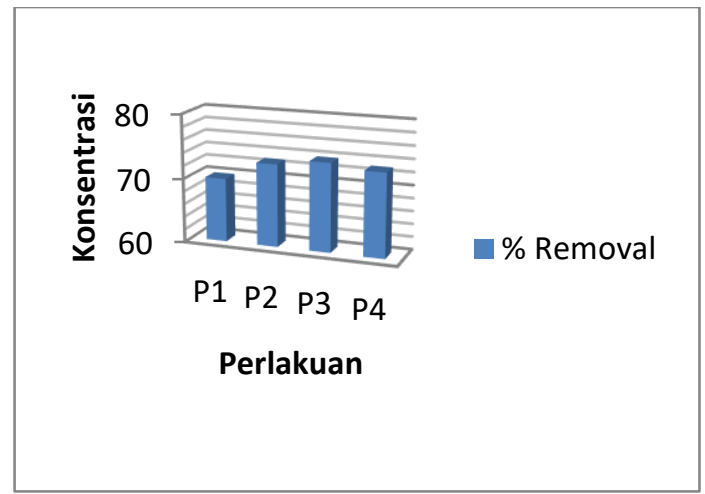

Gambar 1. Persentase Penurunan Konsentrasi Kadmium (Cd) Dalam Air

Berdasarkan Gambar 1 didapatkan persentase penurunan logam kadmium pada keempat variasi perlakuan masing-masing antara lain (P1) sebesar $69.90 \%$,( P2) sebesar 72,86 \%, (P3) sebesar $73.80 \%$ dan (P4) sebesar 73.08 \%. Jadi penurunan kadar kadmium yang paling besar terjadi pada perlakuan P3. Hal ini karena apu-apu mempunyai kemampuan menyerap logam melalui akar. Pada penelitiannya Paramitasari (2014) mejelaskan bahwa Kemampuan penyerapan juga dipengaruhi oleh kandungan kimia dominan yang terkandung dalam organ tumbuhan. Apu-apu mengandung banyak fitokelatin di dalam akarnya. Hal tersebut mempengaruhi pengikatan logam berat oleh organ pada tumbuhan karena fitokelatin. Hasil uji ANOVA pada $\mathrm{p}<0,05$ kadar kadmium dapat dilihat bahwa pengaruh perlakuan terhadap penurunan konsentrasi kadmium dalam air tercemar terjadi perbedaan signifikan antara P1 hingga P4. Semua perlakuan pada penelitian ini menunjukkan penurunan kadar kadmium (Cd). Variasi perlakuan yang mengalami penurunan kadar kadmium dari yang paling besar hingga paling kecil secara berurut yaitu P3, P4, P2,P1.

\section{Penurunan Konsentrasi Tembaga (Cu) Dalam Air}

Dari hasil penelitian menunjukkan bahwa konsentrasi Tembaga dalam air $10 \mathrm{mg} / \mathrm{L}$ menjadi 5.7190 mg/L, $2.1527 \mathrm{mg} / \mathrm{L}, 2.1531 \mathrm{mg} / \mathrm{L}$ dan $1.3384 \mathrm{mg} / \mathrm{L}$ pada ke-4 perlakuan. Berdasarkan data penelitian dapat dijelaskan bahwa terdapat perbedaan signifikan pada setiap perlakuan terhadap konsentrasi logam

Received: April 2021, Accepted : Mai 2021 - Jurnal Photon Vol.11 No.2

DOI : https://doi.org/10.37859/jp.v11i2.2770

PHOTON is licensed under a Creative Commons Attribution-ShareAlike 4.0 International License 
berat tembaga setelah fitoremediasi. Konsentrasi logam tembaga tertinggi pada perlakuan P3 (100 gr apu-apu + $50 \mathrm{gr}$ zeolit) yaitu $1.0537 \mathrm{mg} / \mathrm{L}$ sedangkan yang terendah pada perlakuan P1 $(0 \mathrm{gr}$ apu-apu + 150 gr zeolit). Hal ini terjadi karena apu-apu termasuk tanaman hiperakumulator yang dapat menyerap logam berat pada akarnya . Jadi semakin banyak tanaman apu-apu yang digunakan semakin besar penyerapan logam tembaga. Hasil uji ANOVA pada $\mathrm{p}<0,05$ kadar tembaga bahwa pengaruh perlakuan terhadap penurunan konsentrasi tembaga dalam air tercemar terjadi perbedaan signifikan antara P1 hingga P4. Semua perlakuan pada penelitian ini menunjukkan penurunan kadar tembaga $(\mathrm{Cu})$. Variasi perlakuan yang mengalami penurunan kadar tembaga dari yang paling besar hingga paling kecil secara berurut yaitu P3, P4, P2,P1.

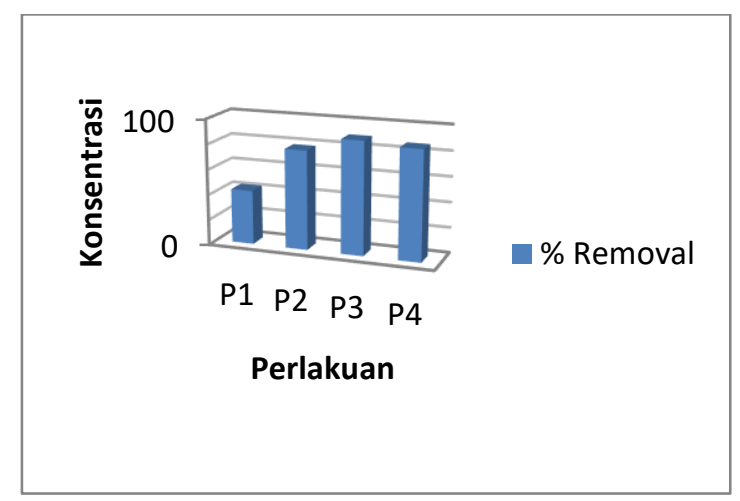

Gambar 2. Persentase Penurunan Konsentrasi Kadmium (Cd) Dalam Air

Dapat dilihat dari Gambar 2 diatas persentase penurunan logam tembaga pada keempat variasi perlakuan masing-masing antara lain (P1) sebesar 42.807 \%, (P2) sebesar $78.473 \%$, (P3) sebesar 89.466 \% dan (P4) sebesar $86.616 \%$. Jadi penurunan kadar tembaga yang paling besar terjadi pada perlakuan P3. Dalam penelitian yang dilakukan oleh Oktaviani et al., (2014) menjelaskan bahwa penyerapan terjadi karena Ion-ion tembaga akan masuk melalui akar tumbuhan secara radial. Mekanisme masuknya ion logam secara radial, mula-mula ion yang terlarut bersama air menembus epidermis akar kemudian translokasi logam berat dari akar ke bagian tumbuhan lain dan lokalisasi logam berat pada bagian sel tertentu untuk menjaga agar tidak menghambat metabolisme suatu tumbuhan.

Received: April 2021, Accepted : Mai 2021 - Jurnal Photon Vol.11 No.2

DOI : https://doi.org/10.37859/jp.v17i2.2770

PHOTON is licensed under a Creative Commons Attribution-ShareAlike 4.0 International License 


\section{Penurunan Konsentrasi Timbal (Pb) Dalam Air}

Dari hasil penelitian menunjukkan bahwa konsentrasi timbal dalam air $10 \mathrm{mg} / \mathrm{L}$ menjadi 1.8757 $\mathrm{mg} / \mathrm{L}, 0.2079 \mathrm{mg} / \mathrm{L}, 0.0934 \mathrm{mg} / \mathrm{L}$ dan $0.1825 \mathrm{mg} / \mathrm{L}$ pada ke-4 perlakuan. Berdasarkan hasil penelitian dapat dijelaskan bahwa terdapat perbedaan signifikan pada setiap perlakuan terhadap konsentrasi logam berat timbal setelah fitoremediasi. Konsentrasi logam timbal tertinggi pada perlakuan P3 (100 gr apu-apu + 50 gr zeolit) yaitu $0.0934 \mathrm{mg} / \mathrm{L}$ sedangkan yang terendah pada perlakuan P1(0 gr apu-apu +150 gr zeolit). Hal ini terjadi karena apu-apu termasuk tanaman Hiperakumulator yang dapat menyerap logam berat pada akarnya . Jadi semakin banyak tanaman apu-apu yang digunakan semakin besar penyerapan logam timbal.

Hasil uji ANOVA pada $\mathrm{p}<0,05$ kadar timbal bahwa pengaruh perlakuan terhadap penurunan konsentrasi timbal dalam air tercemar terjadi perbedaan signifikan antara P1 hingga P4. Semua perlakuan pada penelitian ini menunjukkan penurunan kadar timbal ( $\mathrm{Pb}$ ). Variasi perlakuan yang mengalami penurunan kadar timbal dari yang paling besar hingga paling kecil secara berurut yaitu P3, P4, P2,P1.

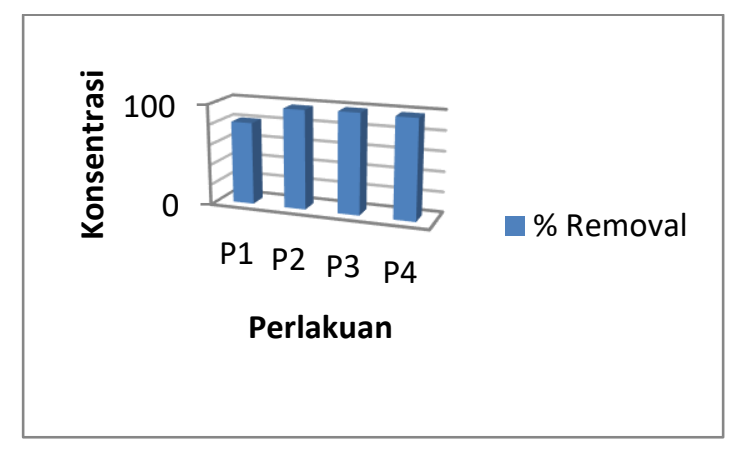

Gambar 3. Persentase Penurunan Konsentrasi Timbal (Pb) Dalam Air

Berdasarkan grafik diatas persentase penurunan logam timbal pada keempat variasi perlakuan masingmasing antara lain (P1) sebesar $81.24 \%$, (P2) sebesar $97.92 \%$, (P3) sebesar $99.07 \%$ dan (P4) sebesar 98.18 \%. Jadi penurunan kadar timbal yang paling besar terjadi pada perlakuan P3. Menurut penelitiannya Caroline dan Moa (2015) mengatakan bahwa tanaman menyerap logam-logam yang larut

Received: April 2021, Accepted : Mai 2021 - Jurnal Photon Vol.11 No.2

DOI : https://doi.org/10.37859/jp.v17i2.2770

PHOTON is licensed under a Creative Commons Attribution-ShareAlike 4.0 International License 
dalam air melalui akar-akarnya. Di dalam akar, tanaman melakukan perubahan $\mathrm{pH}$ oleh akar dan membentuk suatu zat kelat yang disebut fitosiderofor. Fitosiderofor yang terbentuk ini akan mengikat logam dan membawanya ke dalam sel akar melalui transpor aktif. Setelah logam dibawa masuk ke dalam sel akar, selanjutnya logam diangkut melalui jaringan pengangkut xilem dan floem ke bagian tumbuhan lain, yaitu batang/tangkai dan daun. Dan untuk mencegah peracunan logam terhadap sel, tanaman mempunyai mekanisme detoksifikasi, dengan menimbun logam di dalam organ tertentu.

\section{Penentuan Linearitas}

Linearitas menunjukkan kemampuan metode analisis untuk menghasilkan respon yang proporsional terhadap konsentrasi analit dalam sampel pada kisaran atau rentang yang ada (Hane, 2018). Uji ini dilakukan dengan membuat satu seri larutan standar yang terdiri dari konsentrasi yang bertingkat. Larutan standar diukur absorbansinya menggunakan SSA yang telah dioptimasi.

Hasil analisa menunjukkan bahwa terdapat korelasi antara nilai konsentrasi dan absorbansi larutan standar $\mathrm{Cd}, \mathrm{Cu}$ begitu juga dengan larutan standar $\mathrm{Pb}$. Hal ini dibuktikan dengan semakin tinggi nilai konsentrasi larutan standar maka nilai absorbansinya juga semakin tinggi. Nilai korelasi ini dapat terlihat jelas ketika hubungan antara konsentrasi dan absorbansi larutan standar $(\mathrm{Cd}, \mathrm{Cu}$ dan $\mathrm{Pb})$ diwujudkan dalam grafik kurva kalibrasi, dimana konsentrasi larutan standar sebagai sumbu x dan absorbansi larutan standar $(\mathrm{Cd}, \mathrm{Cu}$ dan $\mathrm{Pb})$ sebagai sumbu y dengan persamaan garis $\mathrm{y}=0,5283 \mathrm{x}+0,0167$ dengan koefisien korelasi (r) 0,9992 dan koefisien determinasi (R2) 0,9983 sedangkan data absorbansi dengan deret standar $\mathrm{Cu}$ diperoleh persamaan garis $\mathrm{y}=0,1547 \mathrm{x}+0,0005$ diperoleh dari kurva kalibrasi larutan standar Cu, dengan koefisien korelasi (r) 0,9996 dan koefisien determinasi (R2) 0,9993. Data absorbansi dengan deret standar $\mathrm{Pb}$ diperoleh persamaan garis $\mathrm{y}=0,0232 \mathrm{x}+0,0042$ diperoleh dari kurva kalibrasi larutan standar $\mathrm{Cu}$, dengan koefisien korelasi (r) 0,9989 dan koefisien determinasi (R2) 0,9978. Hasil tersebut menunjukkan bahwa terdapat korelasi antara nilai konsentrasi dan absorbansi larutan standar $(\mathrm{Cd}, \mathrm{Cu}$ dan $\mathrm{Pb}$ ). Hal ini dibuktikan dengan semakin tinggi nilai konsentrasi larutan standar maka nilai absorbansinya juga semakin tinggi dengan demikian regresi liniernya layak diterima karena nilai koefisien korelasinya $\geq 0,995$. Uji lineritas untuk metode penentuan kadar ( $\mathrm{Cd}, \mathrm{Cu}$ dan $\mathrm{Pb}$ ) dalam air

Received: April 2021, Accepted : Mai 2021 - Jurnal Photon Vol.11 No.2

DOI : https://doi.org/10.37859/jp.v17i2.2770

PHOTON is licensed under a Creative Commons Attribution-ShareAlike 4.0 International License 
tercemar menghasilkan koefisien korelasi mendekati 1 sehingga memenuhi kriteria keberterimaan artinya metode yang digunakan untuk rentang konsentrasi yang diukur baik.

\section{Penentuan Presisi}

Uji presisi dilakukan untuk mengetahui kedekatan atau kesesuaian antara hasil uji yang satu dengan yang lainnya pada serangkaian pengujian. Presisi dapat ditentukan dengan \% CV (Coefficient of Varition) jika data dalam bentuk absorbansi. Hasil analisa dapat dilihat bahwa Nilai \% CV < \% CV Horwitz menyatakan metode yang digunakan memiliki presisi yang baik. Hasil ini menunjukkan bahwa metode uji yang digunakan pada penentuan kadar $(\mathrm{Cd}, \mathrm{Cu}$ dan $\mathrm{Pb})$ dalam air tercemar dengan Spektrofotometri serapan atom (SSA) memiliki ketelitian yang baik untuk keempat jenis sampel karena memenuhi syarat yaitu nilai \% CV < \% CV Horwitz (Puspita, 2018).

\section{Conclusion}

\section{A. Kesimpulan}

Berdasarkan penelitian yang telah dilakukan dapat diambil kesimpulan :

1. Pada perlakuan fitoremediasi terjadi perubahan fisik tanaman apu-apu dari daunnya berwarna hijau segar dengan akar panjang yang mengembang bebas diair hingga hari ke -14 daunnya berubah warna kekuningan dan akarnya mengalami kerontokan karena toksitas logam berat

2. Penurunan kadar Cd terlarut dalam masing-masing sampel tertinggi yakni pada perlakuan (P3) sebesar 73.80 \% sedangkan yang terendah yakni perlakuan (P1) sebesar $69.90 \%$, Penurunan kadar $\mathrm{Cu}$ terlarut dalam masing-masing sampel tertinggi yakni pada perlakuan (P3) sebesar 89,46\% sedangkan yang terendah yakni perlakuan (P1) sebesar $42.81 \%$ dan Penurunan kadar Pb terlarut dalam masing-masing sampel tertinggi yakni pada perlakuan (P3) sebesar 99,07 \% sedangkan yang terendah yakni perlakuan (P1) sebesar $81.24 \%$

Received: April 2021, Accepted : Mai 2021 - Jurnal Photon Vol.11 No.2 DOI : https://doi.org/10.37859/jp.v17i2.2770

PHOTON is licensed under a Creative Commons Attribution-ShareAlike 4.0 International License 
3. Hasil Persentase penurunan kadar $(\mathrm{Cd}, \mathrm{Cu}$ dan $\mathrm{Pb})$ menunjukkan perlakuan 3 yang mengalami penurunan kadar logam paling besar dibanding perlakuan lain

4. Uji anova dengan taraf kepercayaan 95\% menunjukkan bahwa terdapat pengaruh perlakuan pada penurunan konsentrasi

\section{B. Saran}

Untuk penelitian selanjutkan disarankan agar menambahkan beberapa data analisa pada metode fitoremediasi yaitu

1. Fitoremediasi dilakukan pada wadah yang lebih luas lagi agar pertumbuhan apu-apu maksimal

2. Analisa konsentrasi logam berat menggunakan instrumen yang lebih canggih lagi agar pendeteksian konsentrasi logam lebih akurat

\section{References}

Abubakar, M. M., Ahmad, M. M., Getso, U. B. 2014. Rhizofiltration of Heavy Metals from Eutrophic Water Using P .stratiotesin a Controlled Environment. Journal of Environmental Science Toxicology and Food Technology (IOSR-JESTFT).Vol 8. No. 6. Hal. 01-03

Amrulloh, A.F. 2017. Penentuan Kadar Logam Timbal (Pb) Dalam Jamu Pegal Linu Menggunakan Variasi Zat Pengoksida Secara Spektrokopi Serapan Atom (SSA). Skripsi. Universitas Islam Negeri Maulana Malik Ibrahim. Malang

Astuti, L. P dan Indriatmoko. 2015. Kemampuan Beberapa Tumbuhan Air dalam Menurunkan Pencemaran Bahan Organik dan Fosfat untuk Memperbaiki Kualitas Air. Jurnal Teknologi Lingkungan. Vol. 19. No. 2. Hal. 184

Bachri, R.N. 2011. Gambaran Kualitas Air Sungai Jeneberang Di Kelurahan Pangkabinanga Kabupaten Gowa Ditinjau Dari Parameter Kadar Timbal $(\mathrm{Pb})$, pH Dan BOD. Skripsi. Universitas Islam Negeri Alauddin. Makassar

Bahri, S., Ramadhan, F., Reihannisa, I. 2015. Kualitas Perairan Situ Gintung, Tangerang Selatan. Jurnal ilmiah biologi. Vol 3. No. 1. Hal 16-22

Baroroh, F., Handayanto, E., Irawanto, R. 2018. Fitoremediasi Air Tercemar Tembaga (Cu) Mengguanakan Salvinia Molesta Dan Pistia Stratiotes Serta Pengaruhnya Terhadap

Received: April 2021, Accepted : Mai 2021 - Jurnal Photon Vol.11 No.2

DOI : https://doi.org/10.37859/jp.v11i2.2770

PHOTON is licensed under a Creative Commons Attribution-ShareAlike 4.0 International License 
Pertumbuhan Tanaman Brassica Rapa. Jurnal Tanah dan Sumber daya Lahan. Vol. 5. No.1. Hal. 689-690

Caroline, J dan Moa, G.A. 2015. Fitoremediasi Logam Timbal (Pb) Menggunakan Tanaman Melati Air (Echinodorus Palaefolius) Pada Limbah Industri Peleburan Tembaga Dan Kuningan. Seminar Nasional Sains dan Teknologi Terapan III 2015 Institut Teknologi Adhi Tama Surabaya

Hastuti, I.W. 2017. Karakterisasi Butiran Sub Mikron Nanomaterial Karbon Batok Kelapa Dengan Variasi Waktu Pengadukan Bahan Yang Digunakan Untuk Filtrasi Logam Fe Dari Limbah Air Selokan Mataram Berdasarkan Uji UV-Vis, XRD, SEM Dan AAS. Skripsi. Universitas Negeri Yogyakarta. Yogyakarta

Hane, A.R. 2018. Validasi Metode Analisis Dan Penetepan Kadar Timbal (Pb) Dalam Air Sungai Gajah ong Yogyakarta Dengan Metode Spektrofotometer Serapan Atom. Skripsi. Universitas Sanata Dharma. Yogyakarta

Herni. 2011. Analisis Cemaran Logam Berat Seng ( Zn) Dan Timbal (Pb) Pada Tiram Bakau (Crassostrea Cucullata) Asal Kabupaten Takalar Dengan Metode Spektrofotometri Serapan Atom (SSA). Skripsi. Universitas Islam Negeri Alauddin. Makassar

Hidayati, E.N. 2013. Perbandingan Metode Destruksi Pada Analisa Pb Dalam Rambut Dengan AAS. Skripsi. Universitas Negeri Semarang. Semarang

Irawanto, R dan Barorah, F. 2017. Kemampuan Tumbuhan Akuatik Salvinia Molesta Dan Pistia Stratiotes Sebagai Fitoremediator Logam Berat Tembaga. Jurnal Prosiding Seminar Nasional Masy Biodiv Indo. Vol. 3 No. 3. Hal. 438-445

Irawanto, R. 2010. Fitoremediasi lingkungan dalam Taman Bali. Jurnal Lokal Wisdom 2. Vol.2. No. 4. Hal. 29-35

Irhamni., Pandia, S., Purba E., Hasan W. 2017. Kajian Akumulator Beberapa Tumbuhan Air Dalam Menyerap Logam Berat Secara Fitoremediasi. Jurnal Kimia. Vol. 4. No.1. Hal. 76-78

Kristianingrum, S. 2012. Kajian Berbagai Proses Destruksi Sampel Dan Efeknya. Prosiding Seminar Nasional MIPA. Universitas Negeri Yogyakarta

Mardikaningtyas, D A., Ibrohim, Suarsini Endang. 2016. Efektifitas Tanaman Pistia Stratiotes Dalam Menyerap Logam Berat Kadmium (Cd) Yang Terkandung Dalam Limbah Cair Pengolahan Tepung Agar Ditinjau Dari Akumulasi Logam Di Organ Akar Dan Daun. Prosiding Seminar Nasional Universitas Muhammadiyah Malang. Vol. 2. Hal. 66-67

Novita E., Hermawan, A., Arunggi, G., Wahyuningsih S. 2019. Komparasi Proses Fitoremediasi Limbah Cair Pembuatan Tempe Menggunakan Tiga Jenis Tanaman Air. Jurnal Agroteknologi. Vol. 13. No. 01. Hal. 16-17

Received: April 2021, Accepted : Mai 2021 - Jurnal Photon Vol.11 No.2

DOI : https://doi.org/10.37859/jp.v11i2.2770

PHOTON is licensed under a Creative Commons Attribution-ShareAlike 4.0 International License 
Nurafifah, S. 2016. Pengaruh Kombinasi Kiambang (Salvinia molesta) dan Zeolit Terhadap Penurunan Logam Berat Kadmium (Cd). Skripsi. Universitas Airlangga. Surabaya

Oktaviani, R., Rachmadiarti, F., Wisanti. 2014. The Potential of Pistia stratiotes and Spirogyra as Phytoremidiation Agent of Heavy Metal Lead $(\mathrm{Pb})$ in Waters. Jurnal Lentera Biologi. Vol.3 No.3. Hal.276-278.

Paramitasari, A. 2014. Kemampuan Tumbuhan Air Kiapu Pistia Stratiotes Dan Kiambang Salvinia Molesta Dalam Fitoremediasi Timbal. Skripsi. Institut Pertanian Bogor. Bogor

Patandungan, A. 2014. Fitoremediasi Tanaman Akar Wangi (Vetiver Zizanioides) Terhadap Tanah Tercemar Logam Kadmium (Cd) Pada Lahan TPA Tamangapa Antang Makassar. Skripsi. Universitas Islam Negeri Alauddin Makassar

Pramudita, A.W. 2015. Validasi Metode Analisis Erdostein Secara KCKT Yang Digunakan Pada Validasi Pembersihan Peralatan Produksi Dengan Cara Usap. Skripsi. Universitas Airlangga. Surabaya

Pratiwi, D.F. 2016. Tingkat Pencemaran Logam Kadmium (Cd) Dan Kobalt (Co) Pada Sedimen Di Sekitar Pesisir Bandar Lampung. Skripsi. Universitas Lampung. Bandar Lampung

Puspita, I.D.R.C. 2018, Verifikasi Metode Penentuan Besi (Fe) Terlarut Pada Sampel Air Filter Layer Menggunakan Spektrofotometer Serapan Atom Di Balai Konservasi Borobodur. Skripsi. Universitas Islam Indonesia. Yogyakarta

Rahayu, S T., Faradilla, M., Verawati, E Y., Triana, M. 2014. Respon Bioakumulator Eceng Gondok (Eichhornia crassipes) Terhadap Logam Berat Pb Dan Cd Di Sungai Pegangsaan Dua. Jurnal Pharm Sci Res, Vol. 1 No. 1. Hal. 10-11

Rahayuningtyas, I., Wahyuningsih, N. E., Budiyono. 2018. Pengaruh Variasi Lama Waktu Kontak Dan Berat Tanaman Apu-Apu (Pistia Stratiotes L.) Terhadap Kadar Timbal Pada Irigasi Pertanian. Jurnal Kesehatan Masyarakat. Vol. 6. No. 6. Hal. 166-172

Rahmawati, D. 2011. Pengaruh Kegiatan Industri Terhadap Kualitas Air Sungai Diwak Di Bergas Kabupaten Semarang Dan Upaya Pengendalian Pencemaran Air Sungai. Tesis. Universitas Diponegoro. Semarang

Raissa, D.G. 2017. Fitoremediasi Air yang Tercemar Limbah Laundry dengan Menggunakan Eceng Gondok (Eichhornia crassipes) dan Kayu Apu (Pistia stratiotes). Skripsi. Institut Teknologi Sepuluh Nopember. Surabaya

Raziah, C., Putri, Z., Lubis, A R., Sofyana., Zuhra., Suhendrayatna., Mulyati, S. 2017. Penurunan Kadar Logam Dalam Air Kadmium Menggunakan Adsorben Zeolit Alam Aceh. Jurnal Teknik Kimia USU. Vol. 6. No. 1 Hal.1-2

Renni, C.P., Mahatmanti, F.W., Widiarti N. 2018. Pemanfaatan Zeolit Alam Teraktivasi Sebagai Adsorben Ion Logam Fe (III) dan Cr (VI). Indo.J. Chem.Sci,Vol. 7 No.1. Hal. 65-66

Received: April 2021, Accepted : Mai 2021 - Jurnal Photon Vol.11 No.2

DOI : https://doi.org/10.37859/jp.v1112.2770

PHOTON is licensed under a Creative Commons Attribution-ShareAlike 4.0 International License 
Rondonuwu, S.B. 2014. Fitoremediasi limbah merkuri menggunakan tanaman dan sistem reaktor. Jurnal Ilmiah Sains, Vol. 14 No.1 Hal. 52-59

Rusnawati., Yusuf, Bohari Dan Alimuddin. 2018. Perbandingan Metode Destruksi Basah Dan Destruksi Kering Terhadap Analisis Logam Berat Timbal (Pb) Pada Tanaman Rumput Bebek (Lemna minor). Prosiding Seminar Nasional Kimia FMIPA. Universitas Mulawarman

Safitri, R. 2009. Phytoremediasi Greywater Dengan Tanaman Kayu Apu (Pistia Stratiotes) Dan Tanaman Kiambang (Salvinia Molesta) Serta Pemanfaatannya Untuk Tanaman Selada (Lactuca Sativa) Secara Hidroponik. Skripsi. Institut Pertanian Bogor. Bogor

Sartika, D. 2012. Studi Kadar Tembaga (Cu) Pada Air Dan Ikan Gabus Di Sungai Pangkajene Kecamatan Bungoro Kabupaten Pangkep 2012. Skripsi. Universitas Hasanuddin. Makassar

Setiyanto, I. 2017. Analisa Kebutuhan Air Bersih (Studi Kasus Instalasi Pengolahan Air Kutoarjo). Skripsi. Universitas Muhammadiyah Purworejo

Sidauruk, L dan Sipayung, P. 2015. Fitoremediasi lahan tercemar dikawasan industri medan dengan tanaman hias. Jurnal Pertanian Tropik 2, Vol 2 No. 2. Hal.178-186

Sulistyorini, I S., Edwin, M., Arung, A S. 2016. Analisis Kualitas Air Pada Sumber Mata Air Di Kecamatan Karangan Dan Kaliorang Kabupaten Kutai Timur. Jurnal Hutan Tropis, Vol. 4 No. 1. Hal. 65-66

Ugya, A.Y., Imam, T.S and Tahir Salisu, M. 2015. The Use Of P.stratiotes To Remove Some Heavy Metals From Romi Stream: A Case Study Of Kaduna Refinery And Petrochemical Company Polluted Stream. IOSR Journal of Environmental Science, Toxicology and Food Technology (IOSRJESTFT). Vol. 9 No.1 Hal. 48-51

Wasir, N.F. 2013. Gambaran Kualitas Air Sungai Tallo Di Kota Makassar Ditinjau Dari Parameter Kadar Timbal ( $P b)$, Bod Dan Cod Tahun 2012. Skripsi. Universitas Islam Negeri Alauddin Makassar. Makassar

Received: April 2021, Accepted : Mai 2021 - Jurnal Photon Vol.11 No.2

DOI : https://doi.org/70.37859/jp.v17i2.2770

PHOTON is licensed under a Creative Commons Attribution-ShareAlike 4.0 International License 